\title{
Kansei - learning: emotional writing work on programming lectures
}

\author{
Alexei Razumowsky ${ }^{1, *}$ \\ ${ }^{1}$ Trapeznikov Institute of Control Sciences of RAS, 65, Profsoyuznaya street, 117997, Moscow, \\ Russia
}

\begin{abstract}
A method of teaching programming is proposed for consideration, which, like Kansei-engineering [1], is based on managing the emotional background in the classroom during classes to enhance the individual significance of the quality of the assignment. The need for the method is due to the fact that during the oral presentation of the material by the lecturer, students today do not use note-taking, and there is also no feedback. The ways of increasing the effectiveness of teaching programming by means of developing the ability to "think with your hands", as an activation of creativity, through the use of additional emotional stress. In this direction, an initiative is proposed to supplement the written dictation at the lecture. It obliges the student not only to implement written decisions, but also to emotionally assess their quality by making special notes in the margins. Such an innovation will allow not only to develop and strengthen the skill of writing software code, but also at the same time to check its correctness individually, since the selfassessment of the quality of the result is formed emotionally. It is assumed that the introduction of regular lecture emotional writing practices will allow students to hone their algorithmic thinking skills more effectively, and the teacher to manage the tendency of individual learning. It can be expected that an emotional insight will occur in the student's mind at a certain moment, associated with the assessment of his own work, which will determine the initial moment of the emerging understanding. An emotional reaction in conjunction with a written result will mean the initialization of an individual educational process.
\end{abstract}

\section{Introduction}

Most of the research on educational problems focuses on cognitive performance with little regard for emotions, and they are extremely important in learning. Thus, it is necessary to consider the presence and quality of significant connections between emotions and design elements of educational material, as well as the classroom space. It is also important to take into account that today's time is characterized by the active use of modern information technology means of interaction and information management by students. For

\footnotetext{
* Corresponding author: razumowsky@yandex.ru
} 
this reason, an extremely urgent problem is to change the traditional forms of education, first of all, lectures. According to [2,3] lectures have the following possibilities: to reveal to students not always available materials; accurately determine the goals, content, organization of the material; supplement and clarify text materials; transfer knowledge to a wide audience. In addition, the advantage of lectures is the ability to participate in group assignments, ask questions and learn "gradually" [34].

The lecture also has its drawbacks [4]: inactive state; lack of opportunity for full discussion; a requirement for the lecturer to have highly effective oratory and cognitive skills.

Many works are devoted to the variety of lectures, both in the educational field and in terms of practical philosophy. So in work [5] the phenomenon of pre-recorded lectures instead of face-to-face lectures and their influence on class attendance and the quality of students' thinking was studied. The work [6,7] is devoted to the problem of creating a feedback context for lectures, however, all the same clickers [8] or a common dialogue space are used for feedback. In [9], the possibilities of game mechanics were studied with the aim of avoiding routine activities in learning. The work [10] records a significant increase in the conceptual perception of knowledge in interactive lectures. The work [11] is devoted to the study of the dependence of the quality of mastering the material on the volume of the lecture space. Meanwhile, the effectiveness in the transfer of knowledge lies in the creation of an emotionally comfortable learning environment.

Kansei technology makes it possible to build the foundation of learning with feedback on the basis of students' emotional reactions $[12,13]$. Unfortunately, a significant number of works are devoted only to online learning [14], and not addressed to the emotions of everyday, everyday life. Such emotion is a full-fledged participant in the processes of cognitive interaction and, therefore, it must be taken into account when making managerial and educational decisions. As indicated in [15], coordination of social, educational and emotional efforts is necessary: «to educate students to be knowledgeable, responsible, socially skilled, healthy, caring, and contributing citizens».

\section{Method}

Consider what constitutes a lecture process in an audience. Then let's pay attention to the changes in the context during the written dictation. Finally, we will involve students' emotional self-esteem in the discussion of educational results.

Each lecture is a dual process of immersion in the essence of the matter, as well as its perception, which are directed towards the birth in the consciousness of genuine personal interest and ideas. Usually, the process that determines the search for and finding an idea is associated with intelligence. However, psychologists also have a different opinion: the author of the idea is the creative activity of a person [16,17], which is important to consider from the point of view of its productivity, feasibility and accompanying emotional reaction. In other words, it is important to isolate the factors of the emergence and support of the creative process, as well as to follow the results of creativity from the point of view of their educational value, expressed by the emotional effect.

Speaking about creativity, usually refer to its 4 stages described by the English pedagogue Graham Wallace (Wallas G) in 1926 [18]: problem analysis, incubation, insight accompanied by emotional experience, and verification. In the educational process, it is very important to rely on the psychological factor of the sudden birth of a solution, understanding an idea, insight - insight. The emotion that accompanies insight is also extremely important.

Let's turn our attention to some of the important factors associated with creativity. First of all, this is the condition for the possibility of the emergence of an insight solution only if 
the key to it is already contained in an unconscious experience [16]. Thus, the accumulated experience is a significant predictor of the development of the final solution. Therefore, the prerequisite for strengthening the dominant of creativity at the lecture will be the condition for the accumulation of individual experience in the general process of responding to the information offered by the lecturer. The next factor of the creative process, which must be taken into account in the formation of comfortable conditions for understanding the idea, is the incubation time of the solution. The third factor in the effectiveness of creativity is the emotion of insight, the moment of awakening of which corresponds to the response to the proposed condition of the problem and the first variant of the solution that arises in the mind.

In [19], it is argued that lectures, as a method of conveying information, are in themselves relatively ineffective in terms of attracting interest in the subject, as well as for teaching behavioral skills. Learning to program should be precisely attributed to the formation of relevant practical skills, habits, techniques, closely correlated, first of all, with cognitive interest and interest in solving specific engineering and practical problems.

To date, a student during the oral presentation of the material by the lecturer is very passive and practically does not use note-taking. Instead, using a smartphone or tablet, they take pictures of graphically expressed slides of lecture presentations or notes on a bulletin board.

It is noticed that the success of the perception of programming knowledge - and this is primarily associated with the acquisition of the skill of writing program code - is determined to a large extent by manual work: taking notes, writing specific tasks, writing or entering program code in the editor. Therefore, the search for an increase in the effectiveness of lecture programming activities should be in the direction of introducing compulsory manual activities into lectures for students. Scientists-inventors also know the expression - to think with their hands, which is required by any truly creative activity [2022]. In addition, any activity, according to Hayek's cognitive theory [23], should combine knowledge, experience and freedom of imagination. Thus, the educational process will become constructive and not only doable. Similar to the effect of free imagination on the basis of emerging experience, liberation of thought should also be expected. Not being constrained by obscure and unusual symbols, but gradually getting used to them, consciousness will suddenly make a leap to some independent idea. This moment will mean the initialization of the individual educational process. This moment is embellished with emotion, and the resulting skill will accompany a decrease in mental effort [24].

Emotional learning is usually associated with testing the meaningful result of the knowledge gained [25-27]. At the same time, direct involvement of the emotional background and participation in the educational process itself is not used, when emotion, along with insight and accumulated experience, affects the quality and speed of cognition. To study the emotional effect in the context of experience and insight, it is necessary to accompany the manual activity of students during the dictation with their emotional introduction into this activity. At least it would be just in the form of an emotional assessment of the results of the quality of one's understanding and the ability to quickly solve a problem.

From a practical point of view, the simplest and most intense way to implement manual work for listeners of programming lectures is a written or oral dictation. Its implementation can serve not only to form and strengthen basic skills, but also as a tool for managing the individual educational process, its pace, content and purposefulness [28,29].

Dictation is generally defined as a type of teaching correct writing to consolidate his skills $[30,31]$. Since in the discipline of programming, skill is just important, first of all, we define a dictation as a student's writing of the program code proposed by the lecturer in the form of a practical task that should be implemented in writing. 
What the dictation is fundamentally deprived of is to control the internal process of knowledge of each student. You can see only the final result, but it is impossible to answer the question of why it is so. Consequently, the teacher remains very limited in the means of managing the effectiveness of lecture work. Emotion is that sign, fact, event that indicates the effect produced, as well as its amplitude. Thus, by fixing his emotion, the student gives the teacher a lever to control his own knowledge. To fix this emotion, an answer to additional questions should be built into the dictation: what is the understanding of the problem and its solution, as well as the student's assessment of the quality of his own solution. In other words, in addition to completing the assignment, the student is obliged to characterize the understanding of the problem and how much he managed to solve it. Initially, there were several attempts to organize emotional self-esteem in the form of a tenpoint scale. However, this had to be abandoned due to the complexity of the choice. Therefore, the emotion is assessed dichotomically: positive / negative.

Many researchers note that self-esteem included in the educational process plays a constructive role, for example [32]. It is assumed that the emotion accompanying creative insight is unconscious and impulsive. In other words, emotional manifestation is not biased and can serve as a pure qualitative measure of an evaluative nature. In the pedagogical literature, there is a research theory of teacher change [33], according to which, through self-assessment, you can significantly improve the professional level. This theory echoes the proposed methodology of emotional self-assessment during problem solving.

Consider the order of Kansei dictation when teaching object-oriented programming in $\mathrm{C}$ ++ . The formulation of the dictated task should be extremely capacious and simple so that no problems of perception arise. Here is an example of such a task: two classes are linked polymorphically; it is necessary to create one object of these types, place them in a vector container, and then copy its contents to a stack container; memory leaks should be avoided.

The text of the decision also contains 2 emotional assessments: self-assessment of the quality of understanding the problem and self-assessment of the quality (reliability) of the solution. As indicated above, such assessments are made dichotomously, according to the principle - either a negative emotion or a positive one. In addition, a condition has been added to place the estimates themselves at the beginning of the report and at its end. This is done in order to reduce the involuntary interference between assessments, that is, selfcopying.

To build a line of corrective teaching, it is important not only to combine emotional assessments with an assessment of the quality of a solution, but also to take into account their contextual interaction. We build a Kansei table for each student and each lecture. Any cell of this table contains a triplet of three assessments: EI, EO and OV, where EI is the student's emotional assessment of his understanding of the problem condition; EOemotional assessment of the quality of one's own decision; and OV is the teacher's assessment (non-emotional). The final estimate $\mathrm{R}$ is established by the formulas:

$$
\begin{gathered}
\forall(E I<0) R=0 \\
\forall(E I>0 \& E O>0 \& O V>0) R=1 \\
\forall(E I>0 \& E O<0 \& O V>0) R=0.75 \\
\forall(E I>0 \& E O<0 \& O V<0) R=0.5
\end{gathered}
$$

Case (1), corresponding to the misunderstood or misunderstood condition of the dictation, is simple. A zero result means you need to adjust the baseline. The next case (2) all positive evaluations $(\mathrm{R}=1)$ - is also easy to interpret as the invariability of the texture of the dictation. The remaining two cases (3) and (4) actually provide the benefits of 
emotional self-assessment according to Kansei technology. It turns out to be possible not only to follow the tendency in the development of knowledge, but also to manage this tendency. Moreover, it should be done with the expectation of individuality, which seems paradoxical for classroom lectures with more than 100 listeners.

However, there are several ways to manage dictation based on Kansei data to anticipate quality results. The first way is to rehearse the term or double it (refrain). For example, instead of the phrase "two classes are linked polymorphically", it should be slightly changed: "two polymorphic classes linked polymorphically". It is important to note that the quality of phrasing can also be slightly reduced. The second way is to add any hints to the problem condition. For example: "the class has a data member of the pointer type intasterisk" (meaning the type of a pointer to an integer - int *). The word "indicative" is emphasized here in order to orient the student to the need to use heap memory for an object of this type, with its obligatory release in the program.

\section{Research results and discussion}

The formulation of the dictation task contains several details that are important for acquiring programming skills, and, first of all, the skill of connecting written work with the work of thought. The results of the lectures with dictation are rather densely described in the previous work [28]. Here we add feedback capabilities. Thus, in processing the results of test dictations, in addition to the correctness of the decision, two emotional assessments accompanying it are taken into account.

When using Kansei dictation, it is extremely important to correctly interpret the numerical results. The result may indicate several intertwined events, each of which has its own individual thread of knowledge. The results obtained weekly corrected the detail, intonation and highlighting of individual phrases in the dictation. We base our foundation on the assumption that each emotion carries with it a sincere response, free from direct reasoning and direct mental working. Such an involuntary impulse of consciousness is akin to a reflex, therefore it is devoid of criticism and controversy. Therefore, we can use the emotion of pure, valid and reliable response as the basis for quality management of the lecture material offered.

The simplest cases are associated with a constant or growing R. Here we can state a positive cognitive process. During the final semester of the survey, the positive dynamics of cognition was confirmed among the students and, as far as it can be discussed, in detail.

Unfortunately, about $10 \%$ of students did not manage to overcome at least a minimum of the cognitive barrier at all. These are cases with $\mathrm{R}<0.5$.

As already emphasized above, the most interesting and abundant Kansei dictation in terms of the diversity of individuality was the positive effect for the group with $\mathrm{R}>0.5$. About a quarter of students from this group in a fairly short period of time (6-8 weeks) raised their grade from $\mathrm{R} \sim 0.5$ to $\mathrm{R} \sim 1$, and were subsequently excluded from this research array. The majority of this most interesting group consisted of students with either not outstanding abilities, but diligent and persistent. Their R-curve was fairly flat, with insignificant growth from $\mathrm{R} \sim 0.5$. Or they are students inclined to creative behavior, expressed individually. They needed a "spark" to ignite a motivating interest in knowledge inside. Such students responded to emotional self-assessment as a game and, being carried away by it, significantly improved their skills. Many of them, during the final survey, offered their own ideas and additions to the method.

The teacher's behavior was determined by the feedback received through the Kansei assessments. After the next lecture, we processed the results, calculated the final grades and filled in Kansei-tables for each student, as well as sometimes graphs in cases where $\mathrm{R}$ changes were wavy. 


\section{Conclusions}

Today, after a semester of experimental application of the Kansei-dictation method, we can confidently state its unconditional viability. Of course, many, many more experiments, checks and corrected estimates are required. However, the quantitative indicators of the number of students who were "kindled" with interest during the training of students to their total number show an increase of about 1.2 times in comparison with last year's results. Future work should be aimed at exploring the correlations between emotional assessments and teacher assessments, as well as exploring the possibility of abandoning the dichotomous approach in favor of wide rating scales.

\section{References}

1. M. Nagamachi, International Journal of industrial ergonomics 15(1), 3-11 (1995)

2. C.M. Chen, C.H. Wu, Computers \& Education 80, 108-121 (2015)

3. F.V. O'Callaghan, D.L. Neumann, L. Jones, P.A. Creed, Education and Information Technologies 22(1), 399-415 (2017)

4. N.T.T. Thai, B. De Wever, M. Valcke, Computers \& Education 107, 113-126 (2017)

5. N. Bos, C. Groeneveld, J. Van Bruggen, S. Brand-Gruwel, British Journal of Educational Technology 47(5), 906-917 (2016)

6. K. Ludvigsen, R. Krumsvik, B. Furnes, Computers \& Education 88, 48-63 (2015)

7. K. Ludvigsen, I.J. Ness, S. Timmis, Thinking Skills and Creativity 34, 100559 (2019)

8. J.E. Caldwell, CBE-Life Sciences Education 6(1), 9-20 (2007)

9. R.K. Pettit, L. McCoy, M. Kinney, F.N. Schwartz, BMC medical education 15(1), 92 (2015)

10. H. Georgiou, M.D. Sharma, European Journal of Physics 36(1), 015020 (2014)

11. E.C. Bolden, T.M. Oestreich, M.J. Kenney, B.T. Yuhnke, Active Learning in Higher Education 20(2), 139-152 (2017)

12. A.N.A. Khairuddin, F. Redzuan, N.A. Daud, International Conference on User Science and Engineering (Springer, Singapore, 2018)

13. P. Turumogan, A. Baharum, I. Ismail, N.A.M. Noh, N.S. Ab Fatah, N.A.M. Noor, Bulletin of Electrical Engineering and Informatics 8(1), 328-335 (2019)

14. F., Redzuan, A.M., Lokman, Z.A. Othman, 3rd International Conference on User Science and Engineering (i-USEr), 168-173 (2014)

15. M.T. Greenberg, R.P. Weissberg, M.U. O'Brien, J.E. Zins, L. Fredericks, H. Resnik, M.J. Elias, American psychologist 58(6-7), 466 (2003)

16. Y.A. Ponomarev, Psychology of creativity (Science, Moscow, 1976)

17. D.V. Ushakov, International Journal of Psychology 31(3-4), 54116-54116 (1996)

18. G. Wallas, The Art of Thought (Harcourt, Brace, and Company, New York, 1926)

19. V.V. Davydov, Soviet Education 30.9, 48-83 (1988)

20. F.H. Cushing, American Anthropologist 5.4, 289-318 (1892)

21. M.W. Thring, E.R. Laithwaite, How to invent (Macmillan, London, 1977)

22. M.I. Alba-Dorado, IV Workshop on Educational Innovation in Architecture (JIDA'16), 1-12 (2016)

23. F.A. Hayek, The American economic review 35(4), 519-530 (1945) 
24. D.A. Norman, Learning and memory (WH Freeman \& Co., 1982)

25. J.A. Durlak, R.P. Weissberg, A.B. Dymnicki, R.D. Taylor, K.B. Schellinger, Child development 82(1), 405-432 (2011)

26. E.T. Rolls, J. Hornak, D. Wade, J. McGrath, Journal of Neurology, Neurosurgery \& Psychiatry 57(12), 1518-1524 (1994)

27. M.T. Greenberg, C.E. Domitrovich, R.P. Weissberg, J.A. Durlak, The future of children, 13-32 (2017)

28. A.I. Razumowsky, International Scientific and Practical Conference on Digital Economy (ISCDE 2019) (Atlantis Press, 2019)

29. C.A. Woodfield, M.B. Mainiero, Journal of the American College of Radiology 5(7), 842-846 (2008)

30. P. Davis, M. Rinvolucri, Dictation: New methods, new possibilities (Ernst Klett Sprachen, 1988)

31. S. Kazazoğlu, Procedia-Social and Behavioral Sciences 70, 1338-1346 (2013)

32. M. Taras, Assessment \& Evaluation in Higher Education 28(5), 549-565 (2003)

33. J.A. Ross, C.D. Bruce, Teaching and teacher Education 23(2), 146-159 (2007)

34. E. Howard, M. Meehan, A. Parnell, International Journal of Mathematical Education in Science and Technology 49(4), 530-553 (2018) 